\title{
Who Goes where: patterns in academic field switching of successful college graduates
}

\author{
Emily C. Wilson and Scott V. Franklin \\ School of Physics and Astronomy, Rochester Institute of Technology
}

\begin{abstract}
We examine patterns of students switching into and out of colleges, STEM/non-STEM fields, and majors within fields, examining the impact of both discipline and demographics. Our data include over fifteen years of student records, with over 22,000 students graduating with an identifiable degree. Restricting the analysis to graduates removes issues of readiness and retention, instead focusing on issues of environment and pathways. We find statistical significance in switching rates of students in colleges of engineering, computer science and applied science and "paths" between colleges that students are more likely to follow as they switch majors. Correlation between persistence within a program and student demographics - gender, ethnicity, and deaf/hardof-hearing status - is strongest in STEM colleges of engineering, computing and applied science and nonSTEM colleges of health science and liberal arts. Connections are seen between colleges of engineering and applied science and between biology (within the College of Science) and non-clinical health sciences, and largescale trends in switching are seen to have changed over time.
\end{abstract}




\section{INTRODUCTION}

The underrepresentation of students and employees in STEM disciplines is well documented, with undergraduate enrollment across the country as low as $14 \%$ [5] and declining [3]. Studies to date have focused on three critical points of the process: entry, retention, and graduation. Enrollment is affected by potential employment opportunities and compensation [12] and degree of social and cultural capital [21, 22]. African American, Latino/a American and Native American (AALANA) students and non-AALANA women comprise $70 \%$ of the U.S. college student population yet are less likely to choose majors [16] and receive degrees [8] within STEM disciplines than white men. $48 \%$ of students initially enrolled in a bachelors program and $69 \%$ enrolled in an associate's degree program within STEM fields leave the discipline or their institution before graduation [6]. Persistence of men correlates with performance, whereas for women persistence correlates with academic environment $[2,17]$. Degree completion and persistence rates are also consistently higher for white students than students of color $[5,6,14,20]$.

Patterns of student switching between programs or majors do not appear to be due to lack of preparation or STEM abilities [11] nor academic difficulty [12]. Rather, changes in major correlate with dissatisfaction with introductory courses and perceived low level of job/money-making opportunities. Changing majors also correlates to higher graduation rates [13], suggesting that students that switch majors are not unprepared for the academic rigor of postsecondary education. Students tend to switch into majors with people who "look like them" [2] with women, in particular, more likely to leave STEM majors $[4,7,10]$. Switching, therefore, is not undesirable in and of itself, but differential switching (between gender, race, etc.) can be an indicator of hostile environment.

White women and ethnic minorities change major more frequently, both in general [12] and from within STEM fields $[4,6,9,14,20]$ than white men. The biological sciences are the source of the largest fraction of non-AALANA women and AALANA students switching majors [9]; engineering is the source of the plurality of male switchers. Orr et al. [15] looked at the differential between students entering and leaving mechanical engineering, finding AALANA students leave more often than they enter, whereas non-AALANA students enter and leave in approximately equal proportions. When students leave STEM fields, there is a high probability that they subsequently declare a business (or business-related) major [2, 4]. An exception is engineering; original engineering majors preferentially switch into computer science fields [7]. Because switching studies require significant longitudinal data most (e.g., 6, 8, 11, 14, 17, 18), even extremely recent ones (e.g. 2), involve students that have graduated before 2010. There is little work comparing the evolution of student switching patterns over time, knowledge that is critical to evaluating current STEM initiatives and formulating plans for future programs to attract students.

This study focuses on a macroscopic view of switching: ignoring for the most part specific programs or majors and instead analyzing students that graduate the institution for changes across fields, defined as STEM vs. non-STEM, or colleges, which define broad disciplines (science, engineering, computing, etc.). Specifically, we ask what are demographic or programmatic features of students that switch programs en route to graduation.

\section{INSTITUTIONAL CONTEXT}

The data for this study consist of student records from 2002-2018 from a technical institute in the northeastern United States. 22, 225 students received an identifiable undergraduate degree and are included in our study. Excluded are 8,457 students that received a graduate degree (which obscures the undergraduate degree in our data set) and 13,169 that left without receiving a degree. The data contain the major (each term), demographic information on gender, race/ethnicity (restricted to African American, Latino/a American, Native American or other), and deaf/hard-ofhearing status (the institute is home to a technical institute for the deaf). The binary reporting of gender is imposed by the institute which, for the time period under study, constrained students to indicate either "male" or "female." Results are thus insensitive to the more nuanced and fluid understanding of gender that has evolved. Similarly, student records identifying race/ethnicity are limited to a binary (AALANA African-, Latino/a, and Native American — or White/other). Doing this, and excluding completely other important ethnic identities (e.g. Asian) is a weakness in this study.

\begin{tabular}{|l|l|}
\hline \multicolumn{1}{|c|}{ College } & \multicolumn{1}{|c|}{ Sample Majors } \\
\hline Engineering & $\begin{array}{l}\text { Electrical Engineering, Mechanical Engineering, } \\
\text { Chemical Engineering }\end{array}$ \\
\hline Computing & $\begin{array}{l}\text { Computer Science, Computing Security, Game } \\
\text { Design, Software Engineering }\end{array}$ \\
\hline Appl. Sci. & $\begin{array}{l}\text { Electrical Engineering Technology, Mechanical } \\
\text { Engineering Technology }\end{array}$ \\
\hline Science & Physics, Math, Chemistry, Biology \\
\hline $\begin{array}{l}\text { Non-clin. } \\
\text { Health Sci. }\end{array}$ & $\begin{array}{l}\text { Biomedical Sciences, Dietetics and Nutrition, Ex- } \\
\text { ercise Science, Physician Assistant }\end{array}$ \\
\hline Non-STEM & $\begin{array}{l}\text { Communication, Psychology, Public Policy, Eco- } \\
\text { nomics, Criminal Justice }\end{array}$ \\
\hline
\end{tabular}

TABLE I. Representative majors for four STEM colleges (Engineering, Computing, Applied Science and Science), Non-clinical Health Sciences and four non-STEM colleges (combined into a single unit).

Degrees are earned in one of nine colleges: computing, engineering, applied science, science, business, art/design, liberal arts, health science, and non-clinical health science. Importantly, all students apply to specific programs within the Institute and thus declare a major upon enrollment. Changing majors is facilitated by advisors who help students navigate the process, which can impact the anticipated time to graduation. Representative degrees are shown in Table I. 


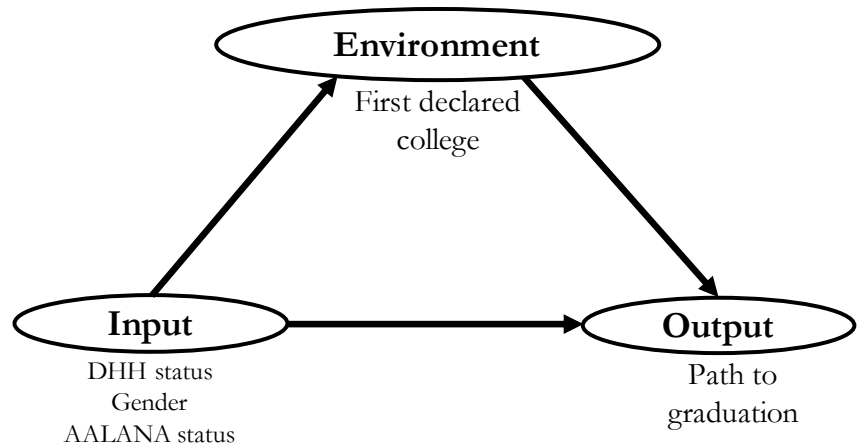

FIG. 1. A schematic of Astin's Input-Environment-Outcome model, adapted from Astin (2012). Arrows show directional connections between model variables.

\section{THEORETICAL FRAMEWORK}

We ground our study in Astin's Input-EnvironmentOutcome (IEO) theory [1]. Illustrated in Figure 1, this model portrays connections between input, environment, and outcome as directional arrows. Inputs are "personal qualities the student brings to the educational program," (gender, AALANA status, and deaf/hard-of-hearing - DHH - status). Environments are "the student's actual experiences during the educational program," in our case characterized by the institute's internal colleges. Our outputs are the students' graduation field and its relation to their incoming program choice. To probe the time-dependence on large time scales we introduce the decade (2002-2010 and 2010-2018) of graduation as a binary environmental factor, dividing our data roughly in half $\left(N_{<2010}=10,015, N_{>2010}=12,210\right)$.

We define persistence $P$ as a student receiving a degree from the same college they declared upon entering. This definition preserves the sense of disciplinary cultural consistency that is embodied by the distinct college. We construct a multivariate regression model of the form

$$
P=\beta_{0}+\beta_{1} x_{1}+\beta_{2} x_{2}+\ldots+\beta_{i} x_{i},
$$

where the $x_{i}$ are the various input and environment factors, including decade. Model coefficients are shown in Table II, with statistically significant coefficients in boldface. Coefficients represent deviations of the mean; the single model is applied to all data and accounts for interaction effects (e.g. impact of being both "Male" and in "Computing.") The data show moderate heteroscedasticity; more complex nonlinear models could be the focus of future research.

\section{RESULTS}

\section{A. Differences by student demographics}

Correlation between persistence and non-AALANA status is strongest in the STEM colleges of engineering, comput-

\begin{tabular}{|c|c|c|c|c|}
\hline & ALANA & Male & DHH & Decade \\
\hline \multicolumn{5}{|c|}{ STEM Colleges } \\
\hline Engineering & $0.122^{\dagger}$ & 0.025 & $-0.253^{\dagger}$ & $0.040^{* *}$ \\
\hline Computing & $0.089^{\dagger}$ & $0.055^{\dagger}$ & -0.009 & 0.009 \\
\hline App. Sci. & $0.072^{\dagger}$ & 0.009 & $-0.084^{*}$ & $0.022^{*}$ \\
\hline Science & 0.036 & -0.015 & -0.054 & 0.112 \\
\hline NC Health Sci. & 0.035 & 0.025 & $-0.268^{* *}$ & 0.052 \\
\hline \multicolumn{5}{|c|}{ Non-STEM Colleges } \\
\hline Health Science & $0.169^{\dagger}$ & 0.009 & 0.061 & 0.044 \\
\hline Business & 0.027 & 0.026 & -0.056 & 0.015 \\
\hline Liberal Arts & $0.062^{*}$ & $-0.084^{\dagger}$ & -0.025 & 0.01 \\
\hline Art/Design & 0.019 & 0.032 & $-0.215^{*}$ & 0.159 \\
\hline
\end{tabular}

TABLE II. Model coefficients for full 2002-2018 data, representing persistence for each group. Coefficients that represent statistically significant differences in persistence are boldface and marked $\left({ }^{\dagger} p<\right.$ $0.001,{ }^{* *} p<0.01,{ }^{*} p<0.05$.)

ing, applied science and in the non-STEM colleges of health science and liberal arts. In all of these cases non-AALANA students persist at rates higher than that of AALANA students. Colleges of computing and engineering show significant differences in persistence rates between students of different genders, with the men students out-persisting women students. Three non-STEM colleges (business, liberal arts and arts/design) show significant differences by gender. In the college of liberal arts, women (a majority of students in that college) are more likely to persist than men. DHH status is significantly correlated with persistence in three of the STEM colleges (engineering, applied science, non-clinical health science) and one non-STEM college (art/design), with hearing students more likely to persist than their DHH peers.

\section{B. Differences across time}

Persistence patterns have changed over time, as seen in the rightmost column in Table II. In all colleges, successful undergraduate students prior to or in 2010 were more likely to maintain their original college than students who graduated after 2010. This is significant in three STEM colleges (engineering, applied science, science) and two non-STEM colleges (health science, art/design). It is important to recall that all of these students subsequently graduated with undergraduate degrees after switching major.

We find that students are switching majors at higher rates in the last nine years than years prior (yet still successfully earning undergraduate degrees). Five colleges have statistically significant variation in college switching pre- and post-2010. All of these cases show increased switching after 2010 as compared to the switching rates before 2010. The colleges for which this increase is significant are the college of engineering, applied science, science, health science, and art/design. The college of science is the only college for which demographics have no intersection with the temporal switching de- 
pendence. The other four colleges which show significant differences in pre- and post-2010 switching rates also show significant differences in at least one demographic.

\section{Difference by STEM/non-STEM field and discipline}

Students who originally declare within STEM/non-STEM colleges persist in their field $92 \% / 96 \%$ of the time, and persistence does not vary greatly across colleges within each field. The majority of students who leave a non-STEM college do so for another non-STEM college. In STEM, however, only students leaving colleges of engineering and science do so (on average) for another STEM college. Students that leave colleges of computing, applied science, and nonclinical health science tend to do so for non-STEM colleges.

Distributions of the paths between colleges for students that switch can be seen in Table III and reveal distinct connections between colleges. If students moved evenly between the five remaining colleges, distributions between all origin and target colleges would be an average $20 \%$. We first note that students who initially declare a major in non-STEM switch fairly evenly between the other five colleges, with the exception being a low percentage into Engineering and a higher percentage into Applied Science. Applied Science houses many Engineering Technology programs, and so the narrative is that $40 \%$ of non-STEM switchers desire some form of engineering, which they satisfy in Engineering Technology programs. Engineering students who switch tend to go mostly to computing and applied science, with very few switching into non-clinical health science and non-STEM. Finally, the switching from science into non-clinical health science and engineering to/from applied science is distinct.

In looking at the connection between non-clinical health science and the college of science, we note a distinct connection between "bio-X" majors (biology, biochemistry, bionformatics, and biotechnology/molecular bioscience). Of the $40 \%$ of students who entered the college of non-clinical health science after leaving the college of science, $83 \%$ are students who originally declared a major that began with the "bio" prefix. Similarly, of the $57 \%$ of students who began in non-clinical health science and switched to science, $75 \%$ earn a degree in either biology or biochemistry.

A similar relationship is found between the colleges of engineering and applied science. In particular, a large proportion of "engineering exploration" majors switch into programs within the college of applied science. The engineering exploration major acts as a springboard to allow undecided engineering students to choose which of several engineering fields is their preference. $70 \%$ of initial engineering exploration students remain in the engineering college, with $13 \%$ in fact switching out of engineering and into applied science. (The next largest path for engineering exploration declarers is to the computing and science colleges, $4 \%$ each.)

\section{INTERPRETATION OF RESULTS}

We interpret Table II in the context of the IEO model, the 9x4 matrix combining demographics, college, and decade. These combinations showed statistically significant differences $(p<0.05)$ in persistence rate between members of opposite demographic groups. In STEM, $50 \%$ of the combinations were significantly different, and in non-STEM colleges, only $37.5 \%$ of the combinations differed across factors.

STEM colleges show more differences across factors than non-STEM colleges. This is consistent with other works; STEM programs show more differences in persistence by demographic than non-STEM programs. Another possible explanation is the technical focus of the institute may contribute to the overall non-STEM persistence rates. The availability and wide range of technical fields, as well as the work experiences afforded students affiliated with the institute, may be the attraction for some fraction of the non-STEM switching students who ultimately leave non-STEM.

We see few differences in persistence by college based on gender, with only colleges of computing and liberal arts showing significant differences. In the computing college men students are more likely to persist while in liberal arts women students are more likely to persist. In all other colleges, persistence is not significantly correlated with gender.

A possible explanation for the lack of gender dependence in other colleges may be other support structures dedicated to persistence and identity (e.g. "Women in Science," "Women in Computing," etc.) to support women. Students, faculty, and staff alike are encouraged to participate in frequent events. In the institute studied, such groups are lacking or less active for other demographics. This is also consistent with our finding that the AALANA/non-AALANA input has an effect on persistence in the colleges of engineering, computing, applied science, non-clinical health science, and liberal arts, where AALANA students persist at significantly lower rates than their non-AALANA peers.

Three of the four colleges that show DHH students persisting at lower rates than hearing students are STEM colleges. Across the U.S., state standards for interpreters are such that being able to translate a technical vocabulary is not a requirement. This leaves $60 \%$ of interpreters unequipped to handle the technical vocabulary that is often seen in STEM fields [19]. Though DHH students at this institute have unparalleled access to interpretation services, the overall reduced ability to translate technical content may contribute to the unequal switching of DHH students in these colleges.

Turning now to the environment-outcome connection, we find that, on average, students who switch out of non-STEM colleges remain in non-STEM majors at higher rates than students who switch out of STEM colleges remain in STEM majors. The individual probabilities of students switching out of certain colleges may suggest trends in which colleges are the most attractive to major-switching students who ultimately maintain their intended STEM/non-STEM field. For instance, we find certain origin-target college pairs to be more 


\begin{tabular}{|c|c|c|c|c|c|c|}
\hline Origin & & & & & & \\
\hline & Engineering ${ }^{\diamond}$ & Computing ${ }^{\diamond}$ & App. Sci ${ }^{\diamond}$ & Science $^{\diamond}$ & N.C. Health Sci. ${ }^{\diamond}$ & Non-STEM \\
\hline Target & & & & & & \\
\hline Engineering $^{\diamond}$ & $X$ & 0.21 & 0.32 & 0.16 & 0.04 & 0.06 \\
\hline Computing $^{\diamond}$ & 0.28 & $X$ & 0.38 & 0.16 & 0.11 & 0.19 \\
\hline App. Sci ${ }^{\diamond}$ & 0.45 & 0.22 & $X$ & 0.15 & 0.11 & 0.36 \\
\hline Science $^{\diamond}$ & 0.16 & 0.30 & 0.14 & $X$ & 0.57 & 0.21 \\
\hline Non-clin. Health Sci. ${ }^{\diamond}$ & 0.04 & 0.05 & 0.03 & 0.40 & $X$ & 0.17 \\
\hline Non-STEM & 0.06 & 0.22 & 0.13 & 0.13 & 0.19 & $X$ \\
\hline
\end{tabular}

TABLE III. Distribution of degree-earners who switch out of the origin college and into the target college. Percentages are normalized to the total number of students who leave each respective college. Values in boldface font exceed twice that which would be expected from random switching. Colleges marked with a diamond $\left(^{\diamond}\right)$ are STEM colleges; non-STEM values reported are averages of the four non-STEM colleges.

than twice as likely as random switching. These include the directional engineering $\rightarrow$ applied science pair and the bidirectional science $\leftrightarrow$ non-clinical health science pairs.

Majors within the engineering college and applied science college have nearly identical titles, though the majors in applied science include the qualifier "technology." The students who wish to have a more applied, and therefore less theoretical, education in an engineering field may migrate toward the applied science college. In fact, we find that students who switch from engineering to applied science often maintain the major concept (e.g., mechanical engineering) but declare in applied science (e.g., mechanical engineering technology). Several faculty in the college of applied science have earned some level of engineering degree and have expertise in engineering technology specifically. This means that the applied science college is a welcome environment for those looking to specialize in a technical field related to engineering.

The college of science and non-clinical health sciences are linked at the major level. Anecdotal evidence supports the notion that students who enter into non-clinical health science from "bio-X" majors do so based on a false notion that a degree and recommendation letter from a health science college is more attractive to medical schools.

\section{CONCLUSIONS AND FUTURE WORK}

In both STEM and non-STEM colleges, demographics within a college have statistically significant effects on persistence. AALANA status and hearing status each show correlation with persistence in three of five STEM colleges (engineering, computing, and applied science); hearing status is significant for the colleges engineering, applied science, and non-clinical health science. Gender shows a strong effect on persistence in only two cases - one STEM college (computing) and one non-STEM college (liberal arts); men students persist at higher rates in computing than women students do whereas women students persist at higher rates in liberal arts than men students do. In many colleges, students who graduated in or before 2010 were more likely to maintain their original college than students who graduated following 2010. When considering the 4 non-STEM environments in combination with the 4 external factors, the non-STEM environments in general show fewer relationships with persistence (6 of 16) than STEM environments (10 of 20). We note that this may correlate with the availability of inclusionary groups specific to each college, rather than similar, national groups.

First-declared college affects both persistence as well as the ultimate degree-granting college. We find strong connections between several colleges, like the strong link between college of science's "bio-X" majors with non-clinical health science and the directional tie between the engineering college and applied science college. These college pairs teach closely related content, perhaps offering more welcoming environments for those who seek a more experimental career path than the one originally set upon.

Results from this work should inform efforts that encourage retention at scales below the institute, i.e. retention within a college, department or program. Future work can include students that do not graduate to examine whether the impact on students that leave an institute altogether react differently to the environmental variables. Additional work should also examine different institutional context, i.e. non-technical institutions, small liberal arts colleges and regional public universities that educate a high percentage of historically underrepresented populations.

\section{ACKNOWLEDGEMENTS}

This material is based upon work supported by the National Science Foundation under Grant No. DUE-1317450. We also gratefully acknowledge members of the RIT Science and Mathematics Education Research Collaborative for productive discussions and other contributions. We also thank Eleanor Sayre for suggestions specific to the composition of the final article. 
[1] Astin, A. (1993). What Matters in College? JB.

[2] Astorne-Figari, C. and Speer, J. D. (2019). Are changes of major major changes? The roles of grades, gender, and preferences in college major switching. Economics of Education Review, 70:75-93.

[3] Beach, G. J. (2013). The U.S. Technology Skills Gap. John Wiley \& Sons.

[4] Bettinger, E. (2010). American Universities in a Global Market. National Bureau of Economic Research, American U:6998.

[5] Chen, X. (2009). Students who study science, technology, engineering, and mathematics (STEM) in postsecondary education. Stats in Brief. NCES 2009-161. Technical Report July.

[6] Chen, X. and Soldner, M. (2013). STEM Attrition: College Students' Paths Into and Out of STEM Fields. Technical report, National Center for Education Statistics, Institute of Education Sciences, U.S. Department of Education, Washington, D.C.

[7] Dickson, L. (2010). Race and gender differences in college major choice. Annals of the American Academy of Political and Social Science, 627(1):108-124.

[8] Gates, S. J. and Mirkin, C. (2012). Engage to excel. Science, 335(6076): 1545.

[9] Griffith, A. L. (2010). Persistence of women and minorities in STEM field majors: Is it the school that matters? Economics of Education Review, 29(6):911-922.

[10] Kugler, A. D., Tinsley, C. H., and Ukhaneva, O. (2017). Choice of Majors: Are Women Really Different from Men? NBER Working Paper No. 23735, page 38.

[11] Lowell, B. L., Salzman, H. H., Bernstein, H., and Henderson, E. (2009). Steady as She Goes? Three Generations of Students through the Science and Engineering Pipeline. Annual Meetings of the Association for Public Policy Analysis and Management, (October):1-57.

[12] Malgwi, C. A., Howe, M. A., and Burnaby, P. A. (2005). Influences on Students' Choice of College Major. Journal of Education for Business, 80(5):275-282.
[13] Micceri, T. (2001). Change Your Major and Double Your Graduation Chances.

[14] National Science Board (2007). National Science Board for Addressing the Critical Needs of the US STEM Education Sys. Technical report, National Science Foundation, Washington, D.C.

[15] Orr, M. K., Lord, S. M., Layton, R. A., and Ohland, M. W. (2014). Student Demographics and Outcomes in Mechanical Engineering in the U.S. International Journal of Mechanical Engineering Education, 42(1):48-60.

[16] Porter, S. R. and Umbach, P. D. (2006). College major choice: An analysis of person-environment fit. Research in Higher Education, 47(4):429-449.

[17] Rask, K. (2010). Attrition in STEM fields at a liberal arts college: The importance of grades and pre-collegiate preferences. Economics of Education Review, 29(6):892-900.

[18] Savkar, V. and Lokere, J. (2010). Time to Decide: The Ambivalence of the World Toward Science Education. Nature, pages $1-14$.

[19] Schick, B., Williams, K., and Kupermintz, H. (2006). Look who's being left behind: Educational interpreters and access to education for deaf and hard-of-hearing students. Journal of Deaf Studies and Deaf Education, 11(1):3-20.

[20] Shaw, E. J. and Barbuti, S. (2010). Patterns of Persistence in Intended College Major with a Focus on STEM Majors. NACADA Journal, 30(2):19-34.

[21] Simpson, J. C. (2001). Segregated by Subject: Racial Differences in the Factors Influencing Academic Major between European Americans, Asian Americans, and African, Hispanic, and Native Americans. The Journal of Higher Education, 72(1):63-100.

[22] St. John, E. P., Hu, S., Simmons, A., Carter, D. F., and Weber, J. (2004). What difference does a major make? The influence of college major field on persistence by African American and White students. 